\title{
Oral candidiasis profile of the Indonesian HIV-infected pediatric patients at UPIPI Dr. Soetomo General Hospital, Surabaya, Indonesia
}

\author{
Mario P. Mensana ${ }^{1}$, Diah S. Ernawati ${ }^{2}$, Alexander P. Nugraha ${ }^{3}$, Bagus Soebadi ${ }^{2}$, Erwin A. Triyono ${ }^{4}$, \\ Dominicus Husada ${ }^{5}$, Remita A. Prasetyo ${ }^{6}$, Sulistyowati B. Utami ${ }^{6}$, Irna Sufiawati ${ }^{7}$ \\ ${ }^{1}$ Undergraduate Student, Faculty of Dental Medicine, Univeristas Airlangga, Surabaya, Indonesia \\ ${ }^{2}$ Department of Oral Medicine, Faculty of Dental Medicine, Universitas Airlangga, Surabaya, Indonesia \\ ${ }^{3}$ Doctoral Student of Medical Science, Faculty of Medicine, Universitas Airlangga, Surabaya, Indonesia \\ ${ }^{4}$ Department of Internal Medicine, Faculty of Medicine, Universitas Airlangga, Intermediate Care and Infectious Disease \\ Centre, Dr. Soetomo Hospital, Surabaya, Indonesia \\ ${ }^{5}$ Department of Child Health, Faculty of Medicine, Universitas Airlangga, Intermediate Care and Infectious Disease Centre, \\ Dr. Soetomo Hospital, Surabaya, Indonesia \\ ${ }^{6}$ Division of Oral Medicine, Dental and Oral Health Unit Dr. Soetomo Hospital, Surabaya, Indonesia \\ ${ }^{7}$ Department of Oral Medicine, Faculty of Dental Medicine, Padjajaran University, Indonesia
}

\begin{abstract}
Introduction: Indonesia is stated as one of Asia's fastest growing HIV epidemics, yet to date, studies on the characteristics of human immunodeficiency virus (HIV) infection, especially on Indonesian children, are very limited. Opportunistic infections, such as oral candidiasis have been an integral part of the disease and related to important diagnostic and prognostic values of the infection. The aim of this study was to determine the candidiasis profile of the Indonesian HIV-infected pediatric patients, and to correlate the clinical types of candidiasis with highly active antiretroviral therapy (HAART) use and the level of immune suppression.

Material and methods: HIV-infected pediatric patients attending the Intermediate Care and Infectious Disease Centre (UPIPI), Dr. Soetomo Hospital outpatient clinic between June-October 2017 were examined intraorally for the presence of oral candidiasis. Identification of Candida species was based on colony morphology on CHROM-Agar, hydrolysis of urea, carbohydrate fermentation tests, thermotolerance test, and microscopic morphology on slide culture from oral swab samples. Other relevant data regarding each patient were also obtained from medical records.
\end{abstract}

Results: Oral candidiasis was found in $55.17 \%$ patients, with 3 different clinical types: pseudomembranous (21.43\%), erythematous (14.29\%), and angular cheilitis $(46.3 \%)$. There was a significant relationship between HAART with erythematous type $(p<0.05)$ and even stronger with the pseudomembranous type of Candida $(p<0.01)$. There was significant relationship between the level of immune suppression and pseudomembranous type $(p<0.05)$ and even stronger with the erythematous type $(p<0.01)$.

Conclusions: Concurrent pseudomembranous and erythematous candidiasis may indicate advanced progression of HIV-infected pediatric patients, therefore further studies are required to validate our findings.

Key words: children, HIV/AIDS, opportunistic infection, oral candidiasis.

Address for correspondence: Prof. Diah S. Ernawati, Faculty of Dental Medicine, Universitas Airlangga, Jl. Mayjend Prof Dr Moestopo 47, 60132, Surabaya, Indonesia, phone: +62 811376403, e-mail: diah-s-e@fkg.unair.ac.id
Article history:

Received: 31.01.2018

Received in revised form: 08.04.2018

Accepted: 30.04 .2018

Available online: 30.11 .2018
International Journal of HIV-Related Problems

HIV \& AIDS

$R$ e vi e w 


\section{Introduction}

Human immunodeficiency virus (HIV) infection in Indonesia is stated as one of Asias fastest growing epidemics [1,2]. Although there had been a national commitment to UNAIDS's "Getting to Zero" goal by 2015, Indonesia failed to cease the spread of new infections within the allocated time frame $[3,4]$. To date, HIV incidence is still high with a rate of 48,000 new cases per year [1]. With 17,000 islands, as the world's largest archipelago country, connectivity between islands become main problem that greatly influence the ability to deliver healthcare services to all parts of the country. Limited access to health centers as well as poor understanding of the symptoms of the disease caused that only $35 \%$ of patients have been diagnosed and $13 \%$ of patients who are already on treatment received help $[1,2,5,6]$. The failure to properly diagnose and treat HIV-infected individuals leads to an enormous spread of the infection to people of all ages, with no exception to newborns. In recent years, the number of HIV-infected infants and children have grown remarkably, with more than $230 \%$ increase from 2010 [7]. To overcome challenges on this growing epidemic, various studies to evaluate characteristics of HIV infection in Indonesia are critical. Opportunistic infections that manifest in the oral cavity has been an integral part of the disease that mirrors the general health of an individual. Of the many oral opportunistic infections, oral candidiasis is the most prevalent manifestation found in immunocompromised host $[8,9]$. It is related to important diagnostic and prognostic values to HIV infection as well as in detecting treatment failure [10]. However, to date, studies on oral candidiasis were dominated by other countries, with scarcely any data from Indonesia, especially on pediatric patients. This aim of this study was to determine the candidiasis profile of the Indonesian $\mathrm{HIV}$-infected pediatric patients, and to correlate the clinical types of candidiasis with highly active antiretroviral therapy (HAART) use and the level of immune suppression.

\section{Material and methods}

The study protocol was reviewed and approved by the Ethics Committee of Dr. Soetomo Hospital (No: 326/ Panke.KKE/V/2017) and the Health Research Ethical Clearance Commission Universitas Airlangga (No: 137/HRECC.
FODM/VIII/2017). Confirmed HIV-seropositive pediatric patients attending the outpatient clinic, Intermediate Care and Infectious Disease Centre (UPIPI), Dr. Soetomo Hospital between June-October 2017 were recruited in this cross-sectional study. The age limit for all pediatric patients was set to 18 years, in consistency with the applied laws and regulations in Indonesia [11]. Prior to oral examination, a written consent was obtained from parents/guardians of the patients. An oral examination was carried out for each Indonesian patient by qualified oral medicine specialists, without prior knowledge of patient's immunologic status or whether the patient had received HAART or not. An examination was conducted while the patient was seated in a dental chair using disposable dental mirrors, sterile gauze pads, and tongue blades under adequate lighting. Oral candidiasis was diagnosed by its clinical features as: 1) pseudomembranous type; 2) erythematous type, and 3) angular cheilitis according to EC-Clearinghouse clinical diagnostic criteria [12]. Microbiological test to identify particular Candida species causing the infection was completed from oral swab sample. Oral swabs were collected from patients presented with oral candidiasis at the time of examination. These swabs were immediately immersed in sabouraud dextrose liquid medium and taken to the laboratory for culture. Candida species were identified based on: colony morphology on CHROM-Agar, hydrolysis of urea, carbohydrate fermentation tests, and thermotolerance test at $42-45^{\circ} \mathrm{C}$ and microscopic morphology on slide culture. Information on patient's immunological status and whether the patient had received HAART or not was obtained from the patient's medical record. Immunological status of each patient was determined by their age-specific CD4 values (CD4\% or CD4 count) within 6 months interval from the time of oral examination, according to the WHO immunological classification (Table 1) [13]. The 6 months' time frame is in accordance with the Indonesian Ministry of Health guidelines on CD4 monitoring [14]. The data obtained were tabulated and subjected to statistical analysis using Statistical Package of Social Sciences (SPSS) 17.0 for windows. Chi-square tests were used to find the significances and associations of oral candidiasis to anti-retroviral therapy and to the level of immune suppression. $P$ values $<0.05$ were considered significant, and $p$ values $<0.01$ were considered very significant.

Table 1. WHO immunological classification for established HIV infection [13]

\begin{tabular}{l|c|c|c|c}
\hline \multirow{2}{*}{$\begin{array}{l}\text { HIV-associated } \\
\text { immunodeficiency }\end{array}$} & $\begin{array}{c}\mid c \\
\text { Age-related CD4 values } \\
\text { (CD4\%) }\end{array}$ & $\begin{array}{c}12-35 \text { months } \\
(\text { CD4\%) }\end{array}$ & $\begin{array}{c}36-59 \text { months } \\
(\text { CD4\%) }\end{array}$ & $\begin{array}{c}>5 \text { years } \\
\left(\text { absolute number per mm }{ }^{3}\right)\end{array}$ \\
\hline None & $>35$ & $>30$ & 25 & $>500$ \\
\hline Mild & $30-35$ & $25-30$ & $15-19$ & $350-499$ \\
\hline Advanced & $25-29$ & $20-24$ & $<15$ & $200-349$ \\
\hline Severe & $<25$ & $<20$ & $<200$ \\
\hline
\end{tabular}


Table 2. Association of different types of oral candidiasis with

\begin{tabular}{|c|c|c|c|c|}
\hline & \multicolumn{2}{|c|}{ No. of patients $(n=28)$} & \multirow{2}{*}{$\begin{array}{l}\text { Chi- } \\
\text { square }\end{array}$} & \multirow{2}{*}{$p$ value } \\
\hline & HAART & HAART naïve & & \\
\hline \multicolumn{5}{|c|}{ Pseudomembranous candidiasis $(n=6)$} \\
\hline Yes & $3(10.71 \%)$ & $3(10.71 \%)$ & \multirow{2}{*}{7.96} & \multirow{2}{*}{$0.005^{* *}$} \\
\hline No & $21(75 \%)$ & $1(3.57 \%)$ & & \\
\hline \multicolumn{5}{|c|}{ Erythematous candidiasis $(n=4)$} \\
\hline Yes & $2(7.14 \%)$ & $2(7.14 \%)$ & \multirow{2}{*}{4.86} & \multirow{2}{*}{$0.027^{*}$} \\
\hline No & $22(78.57 \%)$ & $2(7.14 \%)$ & & \\
\hline \multicolumn{5}{|c|}{ Angular cheilitis $(n=13)$} \\
\hline Yes & $10(35.71 \%)$ & $3(10.71 \%)$ & \multirow{2}{*}{1.53} & \multirow{2}{*}{0.216} \\
\hline No & $14(50 \%)$ & $1(3.57 \%)$ & & \\
\hline
\end{tabular}

*Significant relationship between both variables ( $p$ value $<0.05$ )

${ }^{*}$ Very significant relationship between both variables ( $p$ value $<0.01$ )

\section{Results}

A total of $28 \mathrm{HIV}$-infected patients, 14 (50\%) females and $14(50 \%)$ males, participated in the current study. Participants were between $1-15$ years, with mean age $6.8 \pm 3.1$ years. Oral candidiasis was found in $16(57.14 \%)$ patients with 3 different clinical types. Of these children, 6 (21.43\%) exhibited pseudomembranous type (Fig. 1A and 2), 4 (14.29\%) with erythematous type (Fig. 1B), and 13 (46.43\%) with angular cheilitis (Fig. 3). Analysis of Candida cultures isolated from those lesions identified two different species - Candida albicans (Fig. 4) and C. tropicalis (Fig. 5).

Pseudomembranous type was found in $3(10.71 \%)$ patients on HAART and $3(10.71 \%)$ patients HAART naïve. Erythematous type was found in $2(7.14 \%)$ patients on HAART and 2 (7.14\%) patients HAART naïve. Angular cheilitis was found in $10(35.71 \%)$ patients on HAART and $3(10.71 \%)$ patients HAART naïve. Statistical analysis using Chi-square tests on SPSS 17.0 showed a significant relationship $(p<0.05)$ between HAART and erythematous type, and even stronger relationship $(p<0.01)$ with the pseudomembranous type (Table 2). No patient in the study was classified into advanced immune suppression based on their age-specific CD4 values (Table 1). Pseudomembranous type was found in: 1 (3.57\%) patient with no immune suppression, 1 (3.57\%) patient with mild immune suppression, and 4 (14.29\%) patients with severe immune suppression. Erythematous type was found in $4(14.29 \%)$ patients with severe immune suppression. Angular cheilitis was found in: 7 (25\%) patients with no immune suppression, $1(3.57 \%)$ patient with mild immune suppression, and $5(17.86 \%)$ patients with severe immune suppression. Statistical analysis using Chi-square tests on SPSS 17.0 showed a significant relationship $(p<0.05)$ between the level of immune suppression and pseudomembranous type, and even stronger relationship $(p<0.01)$ with the erythematous type (Table 3).
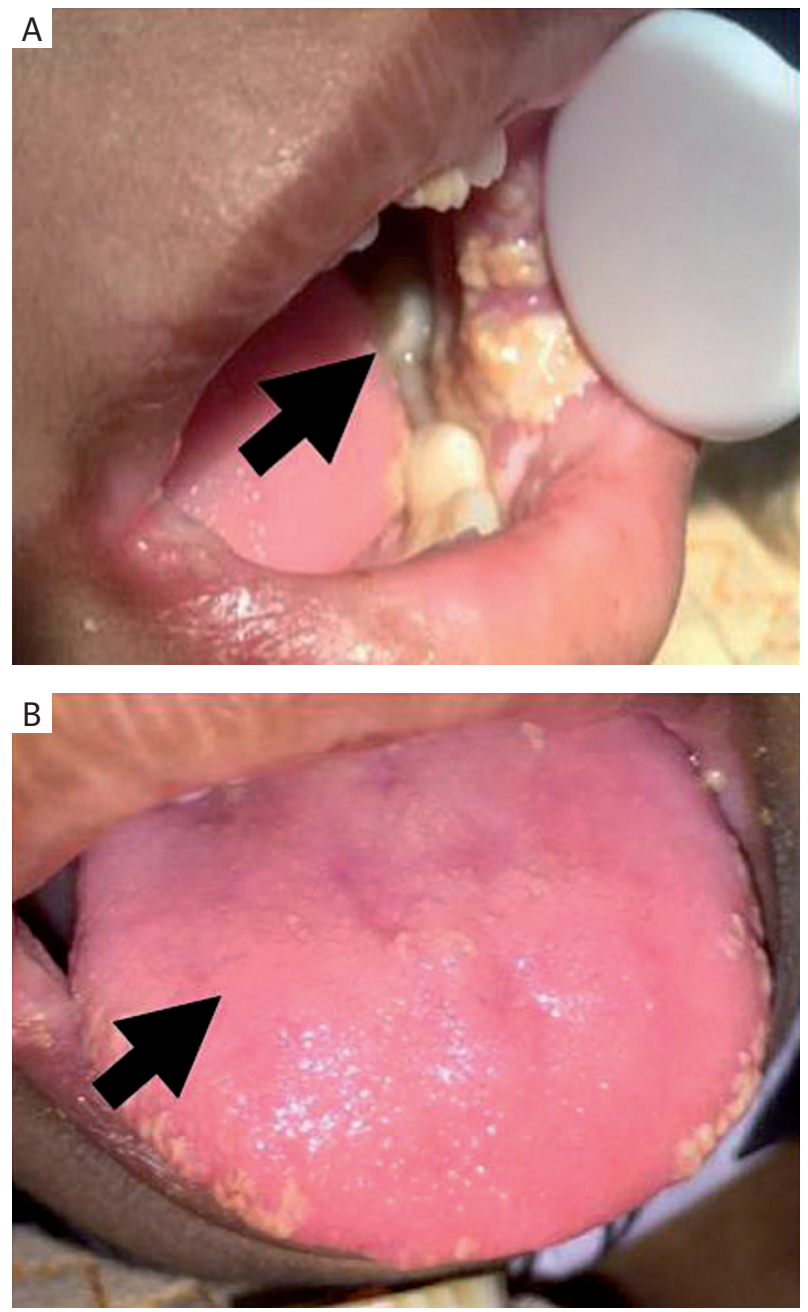

Figure 1. HIV/AIDS infected children with concurrent types of oral candidiasis. A) Pseudomembranous candidiasis on buccal mucosa. B) Erythematous candidiasis on dorsum of tongue

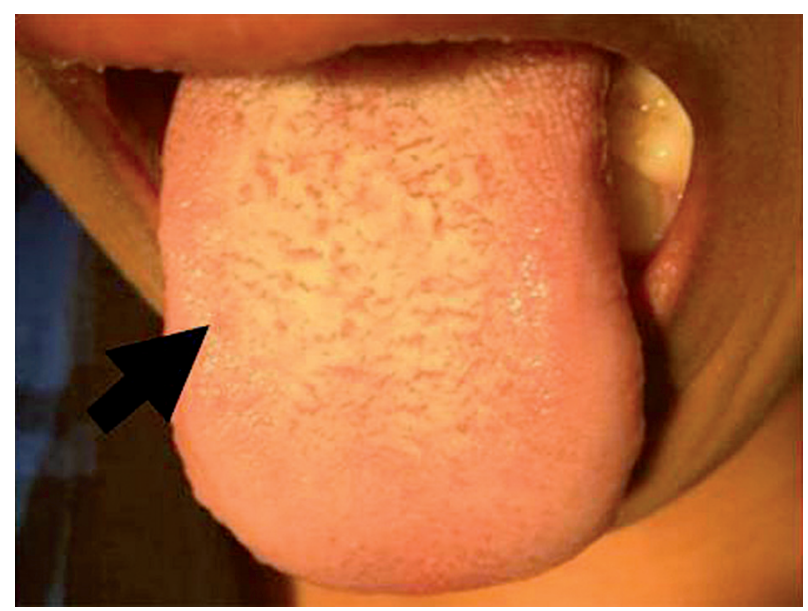

Figure 2. HIV/AIDS infected children with pseudomembranous candidiasis on dorsum of tongue 
Table 3. Association of different types of oral candidiasis with immunological status

\begin{tabular}{|c|c|c|c|c|c|c|}
\hline & \multicolumn{4}{|c|}{ No of patients $(n=28)$ WHO immune suppression classification } & \multirow{2}{*}{ Chi-square } & \multirow{2}{*}{$p$ value } \\
\hline & None & Mild & Advanced & Severe & & \\
\hline \multicolumn{7}{|c|}{ Pseudomembranous candidiasis $(n=6)$} \\
\hline Yes & $1(3.57 \%)$ & $1(3.57 \%)$ & 0 & $4(14.29 \%)$ & \multirow{2}{*}{8.25} & \multirow{2}{*}{$0.041^{*}$} \\
\hline No & $17(60.71 \%)$ & $2(7.14 \%)$ & 0 & $3(10.71 \%)$ & & \\
\hline \multicolumn{7}{|c|}{ Erythematous candidiasis $(n=4)$} \\
\hline Yes & 0 & 0 & 0 & $4(14.29 \%)$ & \multirow{2}{*}{14.00} & \multirow{2}{*}{$0.003^{* *}$} \\
\hline No & $18(64.29 \%)$ & $3(10.71 \%)$ & 0 & $3(10.71 \%)$ & & \\
\hline \multicolumn{7}{|c|}{ Angular cheilitis $(n=13)$} \\
\hline Yes & $7(25 \%)$ & $1(3.57 \%)$ & 0 & $5(17.86 \%)$ & \multirow{2}{*}{2.38} & \multirow{2}{*}{0.498} \\
\hline No & $11(39.29 \%)$ & $2(7.14 \%)$ & 0 & $2(7.14 \%)$ & & \\
\hline
\end{tabular}

*Significant relationship between both variables $(p<0.05)$

**Very significant relationship between both variables $(p<0.01)$

\section{Discussion}

The EC-Clearinghouse clinical diagnostic criteria included oral candidiasis as one of the five orofacial lesions commonly associated with pediatric HIV infection [12, 15]. Previous studies showed that the prevalence of oral candidiasis worldwide could be as high as $88 \%$ in Chilean HIV-positive children without antiretroviral therapy, and $79.1 \%$ in African HIV-positive children who already undergoing antiretroviral therapy. While in Asia, the highest oral candidiasis prevalence among children without antiretroviral therapy was reported to be $57.6 \%$, and among children on therapy it was $45.9 \%$ [10]. In this study, a mix population of children $(n=24)$ undergoing HAART and children $(n=4)$ without HAART resulted in $57.14 \%$ prevalence. This prevalence is in between those studies conducted in Asia. Variation in the prevalence of oral candidiasis can be explained by several factors: characteristics of the studied population, adherence and duration under antiretroviral therapy, and geographical settings [10]. Oral candidiasis is primarily caused by Candida albicans. However, different studies have found an increasing number of non-albicans Candida species to cause the infection. Candida species vary widely in terms of their pathogenicity and virulence in causing an infection as well as their response to anti-fungal regimens [16]. A study from Northern Thailand among perinatally HIV-infected children identified C. albicans as the predominant causative agent, while only 2 cases were found with the respective C. glabrata and C. krusei [17]. In this study, another species, C. tropicalis, was also isolated from pediatric patients. With the advent of antiretrovirals therapies, the prevalence of oral candidiasis has been significantly decreased according to many studies [18-20]. Antiretroviral therapy effectively suppresses HIV replication through various mechanisms and thus allows immune restoration [21]. However, restored immunity does not imply a total eradication of oral candidiasis for those already undergoing HAART, as shown in this study. Pseudomembranous and erythematous types were mostly

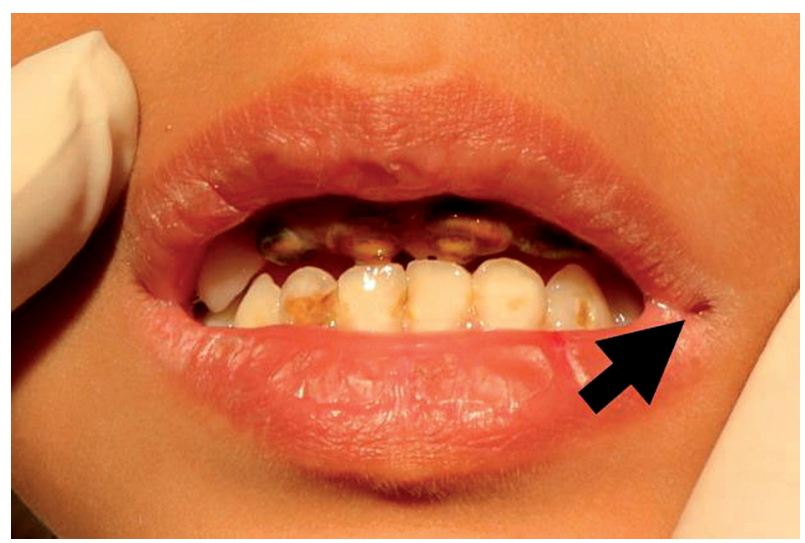

Figure 3. HIV/AIDS infected children with angular cheilitis

absent in patients undergoing HAART. Statistical analysis demonstrates both candidiasis types have significant associations to HAART use, yet no so for angular cheilitis. Different studies on the effect of antiretroviral therapy on oral candidiasis show conflicting results as some studies present significant reduction in prevalence, while others show the opposite [22-24]. In 10 patients undergoing HAART, angular cheilitis was found at the time of oral examination, however, other predisposing factors may explain its occurrence. Decreased vertical dimension due to incomplete teeth eruption during mixed dentition may cause saliva accumulation at the corners of the mouth that predisposes to angular cheilitis [25]. Long-term use of antiretroviral drugs, especially zidovudine, may also cause adverse effects. Furthermore, zidovudine according to studies, can cause anemia. Although patients' anemia could not be confirmed due to the absence of complete blood test corresponding to intraoral examination, it may as well predispose to angular cheilitis [26]. Oral candidiasis in this study was found in varying levels of immune suppression: none, mild, and severe. Patients with oral candidiasis in none or mild immune suppression 

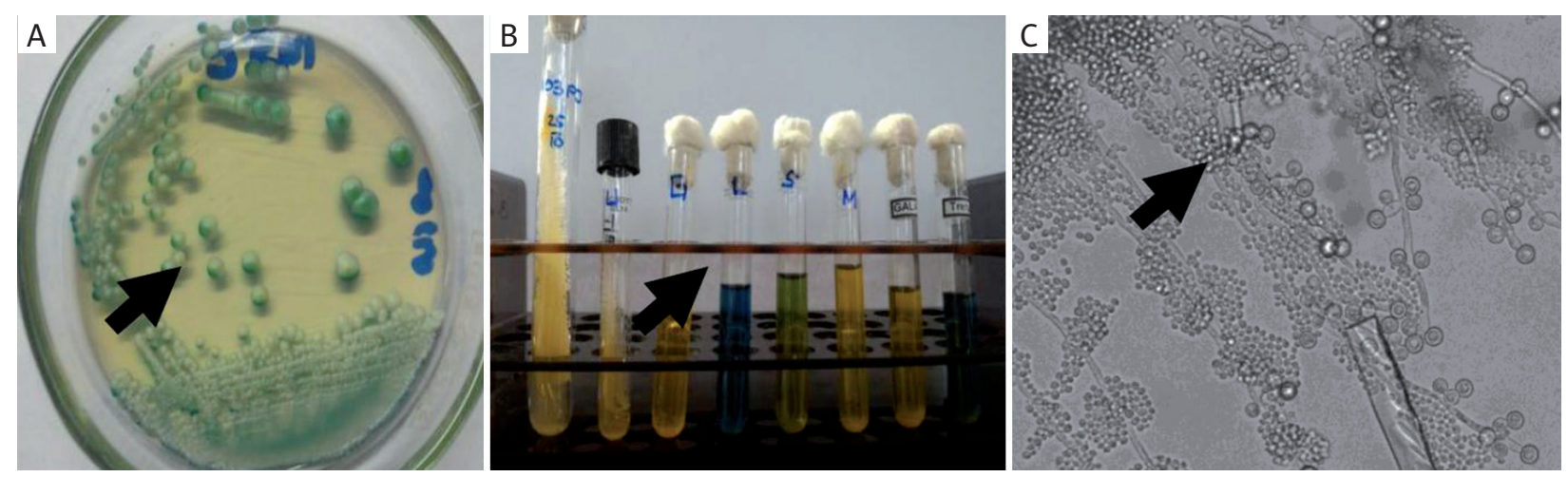

Figure 4. Analysis of Candida cultures. A) Green C. albicans colonies on CHROM-Agar plate. B) C. albicans - hydrolysis of urea and carbohydrate fermentation tests (dextrose, lactose, sucrose, maltose, galactose, trehalose). C) C. albicans microscopic morphology on slide culture
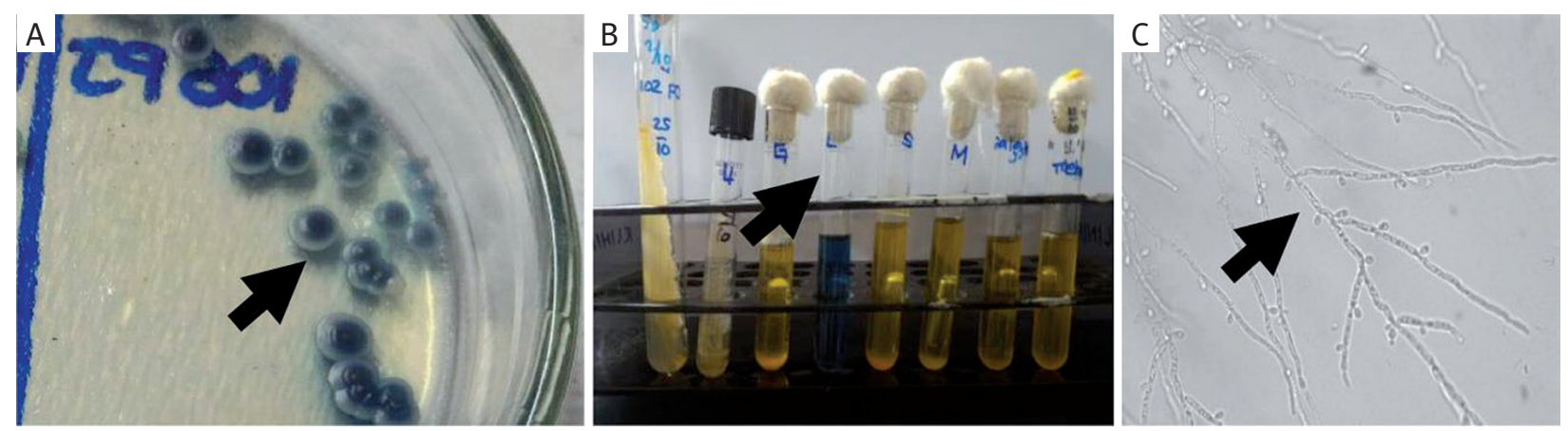

Figure 5. Analysis of Candida cultures. A) Metallic blue C. tropicalis colonies on CHROM-Agar plate. B) C. tropicalis - hydrolysis of urea and carbohydrate fermentation tests (dextrose, lactose, sucrose, maltose, galactose, trehalose). C) C. tropicalis microscopic morphology on slide culture

levels exhibited only one type of oral candidiasis at the time of examination (pseudomembranous type, erythematous type, or angular cheilitis). In contrast, patients with severe immune suppression exhibited more than one oral candidiasis types. Pseudomembranous and erythematous types were mostly absent in patients with none and mild immune suppression levels, yet no so for angular cheilitis. There is no significant difference between the number of children with angular cheilitis and without angular cheilitis in those levels of immune suppression. The aforementioned predisposing factors may contribute significantly to angular cheilitis presence in these patients. The presence of pseudomembranous or erythematous candidiasis in patients with none and mild immune suppression, despite that Candida has low virulence level, might be explained by the interaction between HIV protein and Candida. A study demonstrated that TAT (transcriptional activator) proteins that can be detected in saliva of HIV-infected individuals are able to bind to receptors on C. albicans' cell wall to trigger morphological changes. Following TAT binding to receptors, C. albicans transform from yeast to hyphae to produce secreted aspartyl proteinase (SAP) enzymes. SAP is an excellent extracellular hydrolytic enzyme that is capable of destroying mucosal cell wall of the oral cavity to facilitate adhesion and invasion of C. albicans. This interaction favors oral candidiasis to manifest in the oral cavity [27]. Some patients were also accompanied by symptoms of xerostomia. This was confirmed by the explanations from parents/guardians that an additional fluid was necessary to help their child to swallow food during meal and/or the attachment of buccal mucosa on dental mirrors, once the dental mirror was retracted. Xerostomia is mainly caused (though not absolute) by the lack of salivary gland secretion (hyposalivation). This condition causes antimicrobial molecules, such as secretory immunoglobulin A (sIgA) and beta-defensin, which play important roles in preventing the adhesion and significantly reducing the colonization of Candida to oral mucosa [28-30]. All of these factors might increase the probability of oral candidiasis, although CD4 value was not directly affected.

\section{Conclusions}

Pseudomembranous and erythematous types are both significantly correlated to HAART use and the level of immune suppression. In this study, concurrent pseudomem- 
branous and erythematous candidiasis as seen only in patients with severe immune suppression, may indicate treatment failure and more advanced stage of HIV disease. Further studies are required to assess the coexistent of both types of candidiasis for its sensitivity and specificity to be used as a marker of severely declining immunity.

\section{Acknowledgement}

The authors would like to thank physicians, nurses, staffs, and volunteers of the Intermediate Care and Infectious Disease Center (UPIPI), Dr. Soetomo Hospital for providing technical support throughout this study and for the exceptional assistance provided to the patients.

\section{Conflict of interests}

The authors declare no conflicts of interest.

\section{References}

1. The Joint United Nations Program on HIV/AIDS. UNAIDS data book 2017. Available at: http://www.unaids.org/sites/default/ files/media_asset/20170720_Data_book_2017_en.pdf (Accessed: 10.01.2018).

2. Wisaksana R, Alisjahbana B, van Crevel R, et al. Challenges in delivering HIV-care in Indonesia: experience from a referral hospital. Acta Med Indonesia 2009; 41 Suppl 1: 45-51.

3. The Joint United Nations Program on HIV/AIDS. UNAIDS 20112015 strategy: Getting to Zero. Available at: http://www.unaids.org/ sites/default/files/sub_landing/files/JC2034_UNAIDS_Strategy_en.pdf (Accessed: 14.01.2018).

4. The Joint United Nations Program on HIV/AIDS. ASEAN leaders commit to "Getting to Zero". Available at: http://www.unaids.org/en/resources/presscentre/featurestories/2011/november/20111123a sean (Accessed: 20.01.2018).

5. Pisani E, Olivier KM, Nugroho K. Indonesia's road to universal health coverage: a political journey. Health Policy Plan 2017; 32 267-276.

6. National AIDS Commission Indonesia. National consultation on legal and policy barriers to HIV in Indonesia. Available at: https:/hivlawcommission.org/wp-content/uploads/2017/06/rbaphhd-2015-national-consultation-legal-policy-barriers-hiv-indonesia.pdf (Accessed: 21.01.2018).

7. Directorate General CDC \& EH - Ministry of Health of Indonesia. Laporan situasi perkembangan HIV-AIDS di Indonesia Jan-Maret 2017. Available at: http://www.aidsindonesia.or.id/ck_uploads/files/Laporan\%20HIV\%20AIDS\%20TW\%201\%202017.pdf (Accessed: 10.01.2018).

8. Sharma G, Oberoi SS, Vohra P, Nagpal A. Oral manifestations of HIV/AIDS in Asia: Systematic review and future research guidelines. J Clin Exp Dent 2015; 7: e419-e427.

9. Nazemisalman B, Vahabi S, Bayat N, Ansari A. Early diagnosis of oral manifestation in HIV infected pediatric patients, a review of current literature. Pediatr Neonatal Biol 2016; 3: 001.

10. Gaitán-Cepeda LA, Sánchez-Vargas O, Castillo N. Prevalence of oral candidiasis in HIV/AIDS children in highly active antiretroviral therapy era: A literature analysis. Int J STD AIDS 2015; 26 : 625-632.

11. Indonesian Law and Regulations. Undang-undang Republik Indonesia nomor 23 tahun 2002 tentang perlindungan anak. Available at: http://www.kinerja.or.id/pdf/86547a83-b8d6-461f-afae-f16f968fae8e.pdf (Accessed: 10.04.2017).
12. EC-Clearinghouse. Classification and diagnostic criteria for oral lesions in HIV infection. EC-Clearinghouse on Oral Problems Related to HIV Infection and WHO Collaborating Centre on Oral Manifestations of the Immunodeficiency Virus. J Oral Pathol Med 1993; 22: 289-291.

13. World Health Organization. WHO case definitions of HV for surveillance and revised clinical staging and immunological classification of HIV-related disease in adults and children. WHO Press, France 2007; pp. 14-15.

14. Ministry of Health Republic of Indonesia. Pedoman penerapan terapi HIV anak 2014. Available at: http://www.spiritia.or.id/dokumen/pedoman-hivanak2014.pdf (Accessed: 10.04.2017).

15. Leao JC, Riberiro CMB, Carvalho AAT, et al. Oral complications of HIV disease. Clinics 2009; 64: 459-470.

16. Byadarahally Raju S, Rajappa S. Isolation and identification of Candida from the oral cavity. ISRN Dent 2011; 2011: 487921.

17. Pongsiriwet S, Iamaroon A, Sriburee P, et al. Oral colonization of Candida species in perinatally HIV-infected children in northern Thailand. J Oral Sci 2004; 46: 101-105.

18. Rao KV, Chitturi RT, Kattappagari KK, et al. Impact of highly active antiretroviral therapy on oral manifestations of patients with human immunodeficiency virus/acquired immuno deficiency syndrome in South India. Indian J Sex Transm Dis 2015; 36: 35-39.

19. Ponnam SR, Srivastava G, Theruru K. Oral manifestations of human immunodeficiency virus in children: An institutional study at highly active antiretroviral therapy centre in India. J Oral Maxillofac Pathol 2012; 16: 195-202.

20. Taiwo OO, Hassan Z. The impact of Highly Active Antiretroviral Therapy (HAART) on the clinical features of HIV-related oral lesions in Nigeria. AIDS Res Ther 2010; 7: 19.

21. Wilson EMP, Sereti I. Immune restoration after antiretroviral therapy: the pitfalls of hasty or incomplete repairs. Immunol Rev 2013; 254: 343-354.

22. Flanagan MA, Barasch A, Koenigsberg SR, et al. Prevalence of oral soft tissue lesions in HIV-infected minority children treated with highly active antiretroviral therapies. Pediatr Dent 2000; 22: 287-291.

23. Khongkunthian P, Grote M, Isaratanan W, et al. Oral manifestations in 45 HIV-positive children from Northern Thailand. J Oral Pathol Med 2001; 30: 549-552.

24. Hamza OJ, Matee MI, Simon EN, et al. Oral manifestations of HIV infection in children and adults receiving highly active anti-retroviral therapy [HAART] in Dar es Salaam, Tanzania. BMC Oral Health 2006; 6: 12.

25. Patil S, Rao RS, Majumdar B, Anil S. Clinical Appearance of Oral Candida Infection and Therapeutic Strategies. Front Microbiol 2015; 6: 1391.

26. Montessori V, Press N, Harris M, et al. Adverse effects of antiretroviral therapy for HIV infection. CMAJ 2004; 170: 229-238.

27. Gruber A, Lell CP, Speth C, et al. Human immunodeficiency virus type 1 TAT binds to Candida albicans, inducing hyphae but augmenting phagocytosis in vitro. J Immunol 2001; 104: 455-461.

28. Huber MA, Redding SW, Sankar V, Woo SB. Infectious Disease in Greenberg \& Glick: Burket's Oral Medicine. $12^{\text {th }}$ ed. BC Decker Inc., Hamilton 2015; pp. 560-561.

29. Mahajan B, Bagul N, Desai R, et al. Pseudomembranous Type of Oral Candidiasis is Associated with Decreased Salivary Flow Rate and Secretory Immunoglobulin A Levels. Mycopathologia 2015; 180: 75-80.

30. Vylkova S, Nayyar N, Li W, Edgerton M. Human $\beta$-Defensins Kill Candida albicans in an Energy-Dependent and Salt-Sensitive Manner without Causing Membrane Disruption. Antimicrob Agents Chemother 2007; 51: 154-161 